\title{
Race, ethnicity, and the promise of “Good Food" for Michigan: A three-voice commentary
}

COMMENTARY ON RACE AND

ETHNICITY IN FOOD SYSTEMS WORK

\author{
Rich Pirog a* \\ Michigan State University \\ Kaitlin Koch ${ }^{\mathrm{b}}$ \\ Michigan State University Extension \\ Anel Guel c \\ Michigan State University
}

Submitted June 6, 2015 / Published online August 11, 2015 / Updated with new bibliography link on August 25, 2015

Citation: Pirog, R., Koch, K., \& Guel, A. (2015). Race, ethnicity, and the promise of "Good Food"

for Michigan: A three-voice commentary. Journal of Agriculture, Food Systems, and Community

Development, 5(4), 83-86. http://dx.doi.org/10.5304/jafscd.2015.054.011

Copyright (C) 2015 by New Leaf Associates, Inc.

\section{Abstract}

This set of three interconnected commentaries begins by tracing the evolving narrative of the local food movement to embrace racial equity as a critical part of a sustainable food system in Michigan, using the Michigan Good Food Charter as a potential framework. Researchers, educators,

a * Corresponding author: Rich Pirog is senior associate director for the Michigan State University (MSU) Center for Regional Food Systems and former associate director for the Leopold Center for Sustainable Agriculture at Iowa State University. A native of New Jersey, he is a contributing author of $A n$ Annotated Bibliography of Structural Racism Present in the U.S. Food System, mentioned in this commentary. He can be reached at 480 Wilson Road, Room 302; East Lansing, Michigan 48842 USA; +1-517-353-0694; rspirog@msu.edu

${ }^{\mathrm{b}}$ Kaitlin Koch is currently a community food systems educator for MSU Extension and a native of northern Michigan. and advocates of local food must first have a clear understanding of the structural racism that is present in the American food system before they can work effectively toward the vision of sustainable and equitable food for all. The commentary then calls out the need for new tools and resources for local food students and professionals (including

Her previous work in urban agriculture in Detroit catalyzed her interest in ensuring that equity is an important part of her food systems work.

c Anel Guel is a recent graduate in the Department of Community Sustainability at MSU. Her work ranges from mapmaking and community food systems in Michigan to gender empowerment and ecotourism in Peru. Raised in Juarez, Chihuahua, Mexico, and Grand Rapids, Michigan, she is the lead author of An Annotated Bibliography of Structural Racism Present in the U.S. Food System, mentioned in this commentary. 
Cooperative Extension staff) to better understand the role structural racism plays in the U.S. food system. One new resource identified and developed by two of the commentary authors is an annotated bibliography of structural racism present in the U.S. food system.

\section{Keywords}

racial equity, structural racism, good food, local food systems, Michigan Good Food Charter

\section{Changing the White Narrative in the Local Food Movement: The Promise of the Michigan Good Food Charter by Rich Pirog}

Many white local food systems advocates like myself who were active starting in the 1990s in states with limited racial and ethnic diversity developed a local food narrative focused on economic justice for the mostly white farmer audience we worked with. This well-intentioned approach was myopic in its lack of inclusion for the farmworkers, food processor workers, and foodservice workers (often people of color), as well as for the farmers of color in that same food system. We also overlooked the inequitable policies and history of discrimination that often limited the healthy food choices of people of color in the neighborhoods where they raised their families. We aspired to help build a food systems infrastructure we thought would be sustainable for all. Unintentionally, this particular food system narrative may have contributed to white privilege rather than helped dismantle it.

The local food movement across the U.S. has changed and matured in recent years, with local food becoming an important socioeconomic thread joining an interdependent fabric of movements in health, equity, food justice and sovereignty, and the environment. These movements have the opportunity to expose and reduce racial injustice. We can thank our nonprofits, foundations, new generations of leaders of color, and many others for this convergence. The maturation of local food as part of an interdependent fabric of other movements, combined with recent events exposing racial injustice, has made it paradoxically more difficult, yet inherently more critical than ever, to have meaningful dialogues about the future of our food system across lines of race and ethnicity.

Although an agriculturally and racially diverse state, Michigan has significant disparities across race and ethnicity in regard to quality of life and economic well-being. In both the Detroit and Flint metropolitan areas the median wage for all jobs for workers of color is US $\$ 4$ less than white workers (PolicyLink, 2015). In Grand Rapids, Michigan, the white worker median wage is US\$6 higher per hour than workers of color (PolicyLink, 2015). Obesity rates in Michigan are significantly higher for blacks and Hispanics than for whites (State of Obesity, 2013).

Although equity is likely the most powerful economic development vision we have, there are significant challenges in making that dream a reality. Michigan is fortunate to have developed its local food system plan with equity as an important lens. Michigan's Good Food Charter (http:// michiganfood.org), developed in 2010, envisions a thriving economy, equity, and sustainability for all Michiganders through a community-based good food system, where "good food" means food that is healthy, green, fair, and affordable for all. Currently more than 150 Michigan nonprofit organizations and food-related businesses have signed on to the charter; a significant number of these are working toward one or more of its six goals.

The Michigan Good Food Charter provides all Michiganders working in and across food-related movements a pathway to build a new narrative that answers the question as to why local, healthy, green, fair, and affordable food is so important for our collective future. The equity lens of the charter, in particular, needs more emphasis in this new narrative to identify ways that farmers, farmworkers, food processing workers, and foodservice workers will be treated fairly and be free from exploitation.

The change in narrative for white researchers, educators, and advocates working to promote a "good food" system is essential, and it starts with examining and understanding structural racism in the institutions we work in and the food system as a whole. This is hard, often uncomfortable work and needs introspection, an open heart and mind, and dedicated financial resources in order to 
happen. It means changing the composition of our food systems undergraduate and graduate students, faculty, and staff at our public and private institutions to reflect the people of the state. It means reexamining whether programs, initiatives and hiring practices at our institutions are equitable and accessible for all.

\section{Cooperative Extension's Challenge To Integrate Racial Equity into the Legacy of Present and Future Local Food Professionals}

\section{by Kaitlin Koch}

Michigan State University (MSU) Extension is fortunate to have a Community Food Systems work group with educators working statewide toward the goal of developing local and regional food systems within their communities. As an Extension educator and member of this group, my perspective is that my work group receives a minimal amount of racial equity training. We also have limited opportunities to discuss how racial and ethnic inequities manifest in our work. In Michigan, each MSU Extension employee is required to attend a diversity and inclusion workshop where difference is discussed in depth, and power, inequity, and structural racism are introduced. Unfortunately, that is currently the only required training and space to discuss these issues. There are other resources available, but MSU Extension employees must seek out these limited opportunities.

Additionally, our community food systems work group is mostly white, while a significant number of the communities in which we work are predominately people of color or First Nations people. Without a space for our work group members to examine issues of power, racism, privilege, and how structural racism manifests in the food system, it is quite possible that our work group may be advancing food systems initiatives that disadvantage people of color and ultimately work against our goals of providing equitable opportunities for all people. This outcome is not because our group is intentionally working to advance white privilege and opportunity, but because the system within which we are working is a complex, layered ecosystem of policies and power structures historically built on racial inequity.

To mindfully incorporate racial equity into our work, white Extension professionals need targeted training on undoing racism, power structures, and building authentic relationships with people of color to work in partnership towards the goal of equity. To be most effective, these topics need to be explored within Extension's historical context of inequity. Extension staff members also need a space where we can honestly reflect on how our work and actions are affecting the communities in which we work and identify and name when we, as white educators, have upheld a system of oppression. This work is deep and personal, and requires a lifelong effort of identifying and dissecting our actions. Without these spaces, chances are that the system will push us toward the easiest option or path, which is a path that may disadvantage people of color.

The MSU Center for Regional Food Systems has recently released the publication An Annotated Bibliography on Structural Racism Present in the U.S. Food System (Guel \& Pirog, 2015) that can be found on the center's website and at the link provided below. The bibliography was introduced in May 2015 and citations were added in June 2015 in response to comments received from across the U.S.. This bibliography is an example of a tool that can assist Extension professionals with their personal and professional journey of undoing racism and inequity. I believe that other trainings that focus specifically on undoing racism should be required of all Extension professionals. Such new tools and resources will allow Extension professionals to develop a language and awareness around racism and inequity, which must be used in our conversations with all community partners (and especially in communities of color) to work toward shared goals. These tools will assist the current Extension staff to co-develop educational programs that truly meet the needs of the community in which we work by considering historical context, content, and the cultural appropriateness of messaging. We will become more mindful about who is teaching and who is learning, and how all aspects of each program either work toward equity or reinforce disparity. 


\section{Race, Ethnicity, the Food System, and Academia \\ by Anel Guel}

From the standpoint of a woman of color at a graduate-level academic institution in the Midwest, I have observed and experienced that racial inequities are omnipresent throughout all sectors of U.S. society. As much as this may be a concern, "race" continues to be a difficult conversation to have.

Even in the academic setting one may witness one side feeling guilty or attacked, while the other is left feeling misunderstood or even patronized. Both parties feel sensitive about the issue. Although it may be easy to avoid the issue of race, it is both critical and necessary to have these uncomfortable conversations. This dialogue may become particularly challenging when the work of developing an equitable food system comes from a well-intentioned place. Nonprofits, university institutions, and government organizations are also seeking to "bring good food to others" (Guthman, 2008, p. 431). However, this outreach work bringing good food to communities of color often lacks a fundamental cultural understanding of the communities served. In other words, project development-from assessing community needs to evaluating a project-are often done with little to no involvement from the actual communities served. Work from this standpoint is ineffective, unsustainable, and could even have the potential of causing more harm than good.

Some argue that the groups best able to serve the needs of underserved communities are leaders from those specific communities. Following this train of thought, some even argue that it is white researchers', educators', and advocates' job to "sometimes even stay away" (Guthman, 2008, p. 444) from work focusing on "serving" communities where larger issues are not truly understood. My opinion is that it would be very difficult to reach either of these outcomes and it is questionable whether either truly would be effective. So what can we do now-together? Critically analyzing one's privilege is a step in the right direction, as well as realizing that one does notand probably never will-truly understand the "other's" situation. This goes for white people and people of color alike. I believe the largest leap forward can be made when both parties realize that work is most effective when development projects are collaborative in nature.

Our hope is that An Annotated Bibliography on Structural Racism Present in the U.S. Food System (Guel \& Pirog, 2015) can help open the dialogue for all future college and university students of what role race plays in developing equitable food systemsnot just those who study local food. The intention is that this bibliography, while taking into account the history of structural racism in the U.S. food system, will bring to light larger questions that shape the reality of today's food system and steps we can create together for the future.

An Annotated Bibliography on Structural Racism

Present in the U.S. Food System is available at http://foodsystems.msu.edu/resources/structural racism_in_us_food_system

\section{References}

Guel, A., \& Pirog, R. (2015). An annotated bibliography on structural racism present in the U.S. food system. East Lansing, Michigan: Michigan State University Center for Regional Food Systems. Retrieved from http://foodsystems.msu.edu/resources/structural racism in us food system

Guthman, J. (2008). Bringing good food to others: Investigating the subjects of alternative food practice. Cultural Geographies, 15(4), 431-447. http://dx.doi.org/10.1177/1474474008094315

PolicyLink. (n.d.). National Equity Atlas. Retrieved June 2015 from http://nationalequityatlas.org/

State of Obesity. (2013). The State of Obesity in Michigan. Retrieved from http://stateofobesity.org/states/mi/ 